the skin defect by deep sutures does not seem to be desirable. Flat pressure with early grafting is probably preferable. It might perhaps be better to utilize a large cheek flap with an upper border much longer than required, thus throwing the raw area further out, or to make a second cheek flap to fill in the raw area left by. the first. There does not appear to be any advantage in shaving down the ear cartilage to a thin lamella, but sufficient allowance must be made for the shrinkage of both skin and cartilage, and a very much bigger flap of skin should be supplied than, in the absence of experience, one would have thought necessary. There is no need to fear deformity of the ear if strict asepsis is observed. Very careful dressings are essential, to keep the cornea lubricated, to prepare the granulating area for grafts, to keep these in situ when planted, and to prevent large stitch erosions. Dilute yellow oxide ointment, vaseline, gauze netting, and wet picric acid dressings were employed for these various purposes. Seen three months after operation, the case presented the features shown in the photographs. The obvious defects as observed at this time were: irritation due to the outermost hairs of the upper lid, inaccurate apposition of the outer angle, slight oedema of the upper lid, and shrinkage of the ear flap with a slight entropion. These do not appear to detract from the practical efficiency of the result. The cornea is perfectly covered during closure of the lids.

\title{
COUNCIL OF BRITISH OPHTHALMOLOGISTS
}

\section{Interim Report on the Administration of Optical Benefits by Approved Societies}

In accordance with Section 37 of the National Insurance Act, 1911, an Approved Society in respect of which a surplus, certified by the Government Valuer to be disposable, is found on valuation, may submit to the Minister of Health a scheme for distributing out of such surplus any one or more additional benefits. Amongst these additional benefits is "the payment of the whole or any part of the cost of optical treatment and appliances" (Statutory Rules and Orders, 1921, No. 877).

In October, 1921, the Council of British Ophthalmologists were informed that certain Approved Societies were entering into negotiations with sight-testing opticians for the provision of optical benefit, i.e. examination of the eyes and provision of glasses.

The Council immediately wrote to the Ministry of Health on 
the subject. The following is an extraet from a letter received from the Ministry in reply to this communication :

"Societies which have adopred this particular additional benefit in their schemes have been required, in general, to adopt a schedule in which it is provided that :-

“ 'Optical treatment and appliances' shall not in respect of members resident in Great Britain, include any treatment or appliance provided as part of medical benefit under the National Health Insurance Acts; and further,

"Payment in respect of the cost of an optical appliance shall only be made on the production of a prescription from a qualified practitioner or a hospital, except in cases where the claim is in respect of the renewal of an appliance.

"The Department has not, however, insisted on the inclusion in the scheme of the last-quoted paragraph in any case where a Society desired its omission."

Further correspondence elicited the fact that the above schedule is not contained in any Statutory Rules or Orders, but is merely a model schedule drawn up by the Insurance Department of the Ministry of Health for the guidance of the Approved Societies, so that there is no legal obligation to insist on the acceptance of the paragraph requiring the production of a prescription from a qualified practitioner or a hospital.

Copies of the correspondence between the Council and the Ministry were forwarded to the Departmental Committee on the "Causes and Prevention of Blindness."

In October, 1922, an ophthalmic surgeon wrote to inform the Council that he had been invited by a large Approved Society to act as their consultant ophthalmic surgeon, to whom cases could be sent which the opticians felt they could not treat, the optical benefits hitherto provided by them having been carried out by opticians. The Council informed him that they did not approve of the proposal.

In the spring of 1923 Sir George Berry, M.P., in an informal interview with the Minister of Health laid the views of the Council before him and received a sympathetic reply.

In June, 1923, resolutions passed by the North of England Ophthalmological Society were received by the Council.

In July a committee was appointed by the Council "to consider the question of Administration of Medical (Optical) Benefit by Approved Societies in so far as it affects Ophthalmic Practitioners." The following interim report of this committee was presented at the meeting of the Council and adopted :- 
"The Committee considers that in the list of additional benefits which may be provided by Approved Societies under the National Insurance Act, ${ }^{*}$ it is desirable that for the phrase optical treatment and appliances that of optical appliances prescribed by a medical man should be substituted.

"It recommends that the Council should apply to the Ministry of Health to effect this alteration, pointing out that it is in accordance with the following clause in the model schedule relating to optical treatment issued by the Insurance Department to Approved Societies :

" Payment in respect of the cost of an optical appliance shall only be made on the production of a prescription from a qualified practitioner or a hospital, except in cases where the claim is in respect of the renewal of an appliance.

"Also that the correction of errors of refraction, i.e. optical treatment, cannot be safely carried out without a full knowledge of diseases of the eye, and that at some future date it will be desirable to include ophthalmic treatment amongst the benefits for which provision is made."

The Council proposes to take steps to bring this report to the notice of the Minister of Health and to ask him to receive a deputation.

The dissolution of Parliament and the General Election have prevented them taking any action during the past few weeks.

\section{ANNOTATION}

\section{Miners' Nystagmus}

In our issue of last November we published some comments on a recent article in the Lancet discussing the Second Report of the Miners' Nystagmus Committee of the Medical Research Council. The Committee in that report have to deplore the untimely death of Dr. Rivers. This leaves them without the assistance of any expert in psychology. The findings of this second report strongly emphasize the necessity of appointing a successor. To quote from the Report :

"In Great Britain the disease was first added to the Third Schedule of the Workmen's Compensation Act in 1907. Experience has taught that after a disease is placed in this category several years elapse before claims reach a steady level. In this case a

*Statutory Rules and Orders, 1921, No. 877. Clause 17 of Schedule "The payment of the whole or any part of the cost of optical treatment and appliances." 